\title{
The Enigma of Physics' Quantum Skills Strategies in the Area of Management
}

\author{
Narges Sariolghalam \\ Applied Mathematics, Faculty of Mathematics, Payam e Noor University of Maragheh, Iran \\ Tel: 98- 421-227-5121 Fax: 98-421-227-5125Ｅ-mail:n_ghalam@yahoo.com
}

Mohammad Reza Noruzi (Corresponding author)

Executive Master Business Administration, EMBA, Department of Management and Accounting

Faculty of Humanity Sciences, Islamic Azad University, Kaleibar, Iran

Young Researchers Club Member, IAU Bonab, Iran

Tel: 98- 426-4224915 Fax: 98-426- 422-4917Ｅ-mail: mr.noruzi.pnu@gmail.com

Gholam Reza Rahimi

Public Management, Department of Management and Accounting, Faculty of Humanity Sciences Islamic Azad University, Kaleibar, Iran

Tel: 98- 426-4224915 Fax: 98-426- 422-4917

\begin{abstract}
By using physics quantum skills in the area of management, managers uses from basic science in the area of managerial issues as well and they can look widely for the contemporary issues. This paper aims to review the Intellectual capital (IC) notion and learning organizations (LOs). Also a new perspective to create LOs by implementing competitive strategies like Quantum strategies comes as well.
\end{abstract}

Keywords: Intellectual Capital, Quantum Skills, Learning Organization, Management

\section{Introduction}

The Delphi Group White Paper (2001), drawing upon the work of Edvinsson offers a useful definition, paraphrased as follows. IC can be segmented into three sub-categories: Human Capital, Structural Capital and Customer Capital. Each of these can be considered as valuable assets of an organization in a rather similar way to that of 'goodwill' on that organization's balance sheet. Human Capital is the organization's 'know-how', Structural Capital may be considered as the organizations systems or work processes, and Customer Capital as its relationship with its customers (Thompson, 2010).

In the end, wealth creation in a world of heightened competition comes down to developing and owning difficult to replicate (intangible) assets, and orchestrating them astutely. The latter capability is what I have referred to elsewhere as dynamic capabilities (Teece, 2002). It is estimated that; intellectual capital research has primarily evolved from the desires of practitioners. Consequently, recent developments have come largely in the form of popular press articles in business magazines and national newspapers (Davis, 2009, p.18).

At first this paper has a literature review on intellectual capital and benefits of Intellectual Capital in management and organization. Then the notion of Learning Organizations and Characteristics of a Learning Organization and Associated Best Practices and benefits of learning organizations comes. Finally the quantum organization and Quantum skills for learning organizations and the relationship of the quantum skills to key workplace challenges and the most important factors in quantum strategy in Intellectual Capital practical strategies to creating Intellectual Capital learning system come in details.

\subsection{Benefits of Intellectual Capital in Management and Organization}

Knowledge, competence, and related intangibles have emerged as the key drivers of competitive advantage in developed nations. This is not just because of the importance of knowledge itself, but because of the rapid expansion of goods and factor markets, leaving intangible assets as the main basis of competitive differentiation 
in many sectors. There is implicit recognition of this in both management theory and practice with the growing emphasis being placed on the importance of intangible assets, reputation, customer loyalty, and technological know-how. By using a good structure like learning organization we will have organizational structure that have the ability to support the Intellectual capital in today's market. So today's organizations should try to use this paradigm (learning organizations) to be competitive. Also because our contemporary organizations may differ from the traditional organizations and so we should implement new skills to be learning organization so that our staff can adjust themselves with new technologies. Also can sense the weak signals in the environment and can reply the prosper answer to them. In this situation our managers and executives and CEOs can effectively manage the Intellectual Capital in the organization.

\subsection{IC Measurement}

Plenty of convincing arguments have been forwarded in support of the need to better understand IC via measurement and reporting As discussed, these range from an intuitive understanding that it 'matters' (Stewart, 1997) to evidence that reporting IC has the potential to improve the efficiency of both capital and labor markets Few authors1, however, have traced the sequence of events involved in the development of IC. A historical perspective is important in understanding the context in which IC started appearing in company annual reports. A general timeline of major IC practice and research milestones appears in Table 1(Cuganesan, 2010).

\section{Learning Organizations}

Apparently, learning as the core value of a company is hard to disagree (Senge,1990; Redding,1997)Nevertheless, we may oversimplify the key elements of organization accomplishment and think learning as an omnipotent dose dealing every problem in an organization. Although Seng's conceptual works provide ideal scenery for the management, putting concepts into action is not so easy. Senge believes that all companies should possess the characteristic of a learning organization in order to achieve continuous success. According to Senge, a learning organization can be achieved by practicing five disciplines: a shared vision, personal mastery, strong mental models, group learning, and system thinking(Senge, 1990; 1991). The assumption is quite rational and inexpugnable, but we can soon realize that there is a knowing-doing gap. The job of changing one's mental model and behavior is such big challenge, not even talking about changing the organization as a whole (Lee, 2007).

Another complication is the generalization of management theories proposed in Western culture to other cultures. The five disciplines working well in the West might lead to destruction in the East. For example, Chinese culture respects highly the patriarchal system. Anyone who disagrees with an authority is considered ingratitude. Transplanting different cultural values to another culture without any modification is questionable. Table 1 summarizes the characteristics of IC- knowledge based organizations (Lee, 2007).

\subsection{Benefits of being a Learning Organization}

Twenty first century is the century of knowledge and there are many benefits to improving learning capacity and knowledge sharing within an organization. The main benefits are;

- Adapting better than your competitors to external pressures

- Systemizing innovation and new ideas

- having the knowledge to better link resources to customer needs

- Improving quality of outputs at all levels

- Increasing the pace of change within the organization

- Improving company image by becoming more people-orientated

According to Peter Senge the 5 dimensions that distinguishes learning from more traditional organizations is the mastery of certain basic disciplines or 'component technologies'. Are:

1) Systems thinking

The ability to see the big picture and identify patterns and themes instead of individual events. Senge argues we tend to apply overly simplistic frameworks to complex systems; focusing on the parts instead of the whole. Classically we look to actions that produce improvements in a relatively short time span. However, when viewed in systems terms short-term improvements often involve very significant long-term costs. We may learn from experience but a simplistic short term view may mean we never learn. The argument runs, a better appreciation of systems will lead to more appropriate action(Learning Organization, 2005). 


\section{2) Personal mastery}

Organizations only learn when individuals learn but individual learning does not guarantee organizational learning. People with personal mastery are continual learners and are aware of their short comings, development needs and ignorance yet they have the self confidence to be active learners.

3) Mental models

This is about understanding that our assumptions and generalizations profoundly influence how we see the world and the decisions and actions we make. The process here is to uncover those assumptions or mental models and test them. It is also about balancing advocacy and inquiry and avoiding non-productive corporate games and politics. It is also about more distributed and local team ownership In other words it is about fostering a mental flexibility and openness (Learning Organization, 2005).

4) Building shared vision

The emphasis is on a "shared vision" which means collaborative development to foster genuine engagement and commitment rather than just compliance. This is the exact opposite of a CEO selling a vision. Visions spread because of a reinforcing process. Increased clarity, enthusiasm and commitment rub off on others in the organization. 'As people talk, the vision grows clearer. As it gets clearer, enthusiasm for its benefits grow. Shared visioning build commitment for the future(Learning Organization, 2005).

\section{5) Team learning}

This is about discussion and team alignment; it is about creating the results that the team desires. It builds on vision and personal mastery but these are not enough. Teams have to learn to work and learn together. It is about team disciplines and the quality of the team's discussions and insights. When teams learn together, Peter Senge suggests, not only can there be good results for the organization; members will grow more rapidly than could have occurred otherwise (Learning Organization, 2005).

\subsection{Intangible Assets Era}

As the 1990's ended, the business environment became one of virtual offices using complex networks and sophisticated technology for communication and aggregating data. The desirable employees for this millennium were knowledge-workers who knew and understood the organizational strategy and were able to aggregate information, synthesize and analyze data, make decisions instantaneously, and implement them independently (Chiavenato, 2001; Daft, 2001). In the virtual corporate environment employee judgment has to be trusted and depended on to be representative of the organization without the luxury of drawing consensus, accessing team input, and without supervision and mentoring of a manager down the hall or two floors above. This environment mandates that organizations optimize their employee corporate awareness, knowledge, and interconnectivity: their intellectual capital. Employee skills and core competencies are expected to be present while it is the employee's sought (Ulrich, 1997; Roos et al., 1998; Guthrie, 2001). Organizations need to look at their human resources and identify the intellectual capital necessary to provide sustainable momentum for the organization's competitive advantage (Edivsson et al., 1997; Roos et al., 1998; Carrel 2010).

\section{The quantum skills of Physics}

At about the same time that Taylor and Fayol were developing management theories congruent with the Newtonian worldview, Einstein was conducting experiments that eventually turned this worldview upside down. Einstein discovered that in the realms of the very small (subatomic) and the very large (cosmic), Newton's laws are null and void. By the 1920s, this discovery launched a new branch of physics called quantum mechanics. The word quantum literally means "a quantity of something"; mechanics refers to "the study of motion". Quantum mechanics is, therefore, the study of subatomic particles in motion (Shelton, 1999, pp. 1-2). According to quantum theory, the universe is basically a set of signals or a field of information. It is much more like a great thought than the great machine metaphor of the Newtonian paradigm (Shelton \& Darling, 2003, pp.358-359).

\subsection{The quantum- Physics organizations and Quantum Skills for Learning Organizations}

As leaders use these quantum skills, they create what Shelton (1999) refers to as quantum organizations organizations where all stakeholders know how to access the infinite potential of the quantum field. Quantum organizations are, therefore, learning organizations - places where continuous improvement and constant learning are cultural norms. Table I shows the relationship of each quantum skill to seven contemporary workplace challenges: quality, innovation, motivation, empowerment, social responsibility, change, and diversity. As leaders adapt new mental models that are congruent with the quantum worldview, they will discover highly innovative ways of dealing with these organizational challenges (Shelton \& Darling, 2003, pp.358-359). 
According to quantum theory of Physics, the universe is basically a set of signals or a field of information. It is much more like a great thought than the great machine metaphor of the Newtonian paradigm. The quantum worldview, which characterizes the universe as a dynamic, unpredictable, subjective, self-organizing system, provides the conceptual foundation for seven quantum skills - skills that enable leaders to surface and test their mental models and thus improve their capacity to learn. The quantum skills are defined as follows:

(1) Quantum seeing: the ability to see intentionally.

(2) Quantum thinking: the ability to think paradoxically.

(3) Quantum feeling: the ability to feel vitally alive.

(4) Quantum knowing: the ability to know intuitively.

(5) Quantum acting: the ability to act responsibly.

(6) Quantum trusting: the ability to trust life's process.

(7) Quantum being: the ability to be in relationship (Shelton, 1999, p. 4; Shelton \& Darling, 2003, pp.354-355).

The summary of quantum theory is summarized below in table II:

3.2 The Most Important Factors in Physics Quantum Strategy in Intellectual Capital Management Practical Strategies to Creating Intellectual capital learning system

(1) Individual learning is an emergent process that seems to arise through interaction and seems to depend on a number of factors, of which the most important are:

- Who an agent met

- How often an agent met a certain other agent

- Which characteristics the agents respectively had

- The characteristics of the agents, i.e. how much does an agent trust other agents, how motivated is an agent, how orderly, etc.

(2) Whether collective learning takes place depends on the composition of the team and their characteristics. That will eventually determine whether a group of agents will reach their group threshold.

(3) How quick an agent learns, depends on his characteristics and the characteristics of the agent he meets.

(4) An agent can learn, but he can also "unlearn" if his motivation and trust drop.

(5) Agents that represent R\&D people and marketing managers seem to learn faster.

(6) The extent to which a senior manager slackens his control is determined by the degree of trust he has in the project manager, which in turn depends on the degree of trust a project manager has in other agents.

(7) A run of the model wherein senior managers were left out of the hierarchy showed that learning took place faster than in prior cases which hinted at the existence of self-organization (Harkema, 2003, pp.344-345).

\section{Conclusions}

It has long been recognized that 'economic prosperity rests upon knowledge and its useful application' (Teece 1981). Indeed, 'the increase in the stock of useful knowledge and the extension of its application are the essence of modern economic growth' (Kuznets 1966). Enlightened economic historians have long emphasized the role of technology and organization in economic development.

Most organizations have adapted or transformed their management styles and business models to manage intellectual capital (IC) and respond to the IC-enabled dynamics of the knowledge economy. Many of these organizations have done it without even realizing that they are adopting an intellectual capital management (ICM) approach. A top executive of a leading consumer products company, whose name is withheld, commented that his company is not interested in ICM. "Show me the money," he said. "All I see are the circles and pyramids that ICM people draw in conferences." What this executive did not realize is that he was already managing IC in one way or another on a daily basis to make money. If it weren't for this executive's daily reliance on his gut feeling and tacit knowledge to manage his employees' innovation, the company he works for wouldn't be a market leader. If the company's employees did not care about the management of customer and structural capital, it wouldn't invest millions of dollars in its interactive Web site to solicit consumers' feedback 24 hours a day, seven days a week (ICM, 2009). 
By using a good structure like learning organization we will have organizational structure that have the ability to support the Intellectual capital in today's market. So today's organizations should try to use this paradigm (learning organizations) to be competitive. Also because our contemporary organizations may differ from the traditional organizations and so we should implement new skills to be learning organization so that our staff can adjust themselves with new technologies. Also can sense the weak signals in the environment and can reply the prosper answer to them. In this situation our managers and executives and CEOs can effectively manage the Intellectual Capital in the organization.

Also doing a successful strategy and transferring a traditional organization to a knowledge-based one, and keeping and accumulating the IC and intangible resources in the organization more efficient, organizations should use from LO and knowledge accumulate strategies and professional team building strategies in their organizations to survive and growth and dynamical capability in today's' competitive era (Hung et al, 2005; Groves, 2002; Levet \& Guenor, 2000).

Formalization, the sharing of personal knowledge, and the development of structural approaches as a mechanism to transfer learning throughout the firm may on the other hand sap creativity and impede learning. Ideally, one would like to develop approaches or models which have a common essential logic, but which enable customization of particular features. This is but one of the many challenges to service firms in the new economy where knowledge sharing itself can often be the basis of competitive advantage (Teece, 2002).

In the modern knowledge intensive business environment, most organizations stand to gain a substantial prize in terms of innovative ideas, but these need to be coaxed out to win that prize. Part of that coaxing is likely to include an imperative of innovation as an ongoing activity to gain competitive position, and in turn managers will need to heed the foregoing points on organization (Thompson, 2010).

\section{References}

Argyris, C. and Schön, D. (1996). Organizational learning II: Theory, method and practice, Reading, Mass: Addison Wesley.

Argyris, Chris. (1991). "Teaching Smart People How to Learn." Harvard Business Review. May-June 1991. pp99-109.

Carrell, Jan (2010). an Epistemology of Intellectual Capital and its Transition to a Practical Application, Strategic Intellectual Capital Management in Multinational Organizations: Sustainability and Successful Implications, Kevin J. O'Sullivan, Business Science Reference (an imprint of IGI Global) ISBN 978-1-60566-679-2.

Chiavenato, I. (2001). Advances and challenges in human resource management in the new millennium. Public Personnel Management, 30(1), 17-26.

Cuganesan, Suresh - Richard Petty. (2010), Intellectual Capital Measurement and Reporting: Issues and Challenges for Multinational Organizations, Strategic Intellectual Capital Management in Multinational Organizations: Sustainability and Successful Implications, Kevin J. O'Sullivan, Business Science Reference (an imprint of IGI Global) ISBN 978-1-60566-679-2.

Daft, R. L. (2001). Organization theory and design, (7th ed.). Mason, OH: South-Western

Davis, Mark, (2009). The value of knowledge management, available online at: http://www.knowledgepoint.com.au/intellectual_capital/Articles/IC_MD001c.htmlDemset

Edvinsson, Leif and Michael Malone (1997). Intellectual Capital: The Proven Way to Establish Your Company's Real Value by Measuring Its Hidden Brainpower. London: Biddles Ltd.

Guthrie, J. (2001). The management, measurement and the reporting of intellectual capital. Journal of Intellectual Capital, 2(1), 27-41. doi:10.1108/14691930110380473

Harkema, Saskia, (2003), A complex adaptive perspective on learning within innovation projects, The Learning Organization, Volume $10 \cdot$ Number $6 \cdot 2003 \cdot$ pp. 340-346, $q$ MCB UP Limited · ISSN 0969-6474, DOI $10.1108 / 09696470310497177$.

ICM, (2009). Intellectual Capital Management, Comprehensive Intellectual Capital Management, visited: July 2009, available at: http://www.wdc-econdev.com/

Kuznets, S. (1966). Modern Economic Growth: Rate, Structure, Spread. New Haven, CT: Yale University Press.

Lee, An Ti, (2007). CULTURAL BARRIERS TO THE LEARNING ORGANIZATION IN CHINESE SOCIETY, 
Learning Organization, (2005), What is a Learning Organization?, available online at: http:/www.leopard-learning.com/learningorganization.html

Redding, J,( 1997)."Hardwiring the Learning Organization, ”Training and Development,( August),61-67.

Roos, J., Roos, G., Edvinsson, L., \& Dragonetti, N. C. (1998). Intellectual capital: navigating in the new business landscape. New York: New York University Press.

Senge, P.M.( 1990).’The Leader's New Work: Building Learning Organization,” Sloan Management Review, (Fall),7-23.

Shelton, C. (1999). Quantum Leaps, Butterworth-Heinemann, Boston, MA.

Shelton, Charlotte D, Darling, John R. (2003), Using new science concepts to create learning organizations, The Learning Organization Volume 10, Number 6 $2003 \cdot 353-360$

Stewart, T.A. (1998). Intellectual Capital, Nicholas Brealy Publishing, London

Teece, J. David, (2002). Managing Intellectual Capital Organizational, Strategic and Policy Dimensions, Oxford University Press, OUP

Thompson Alan M. (2010). Facilitating the use of Intellectual Capital in a Matrix Multinational Organization, Strategic Intellectual Capital Management in Multinational Organizations: Sustainability and Successful Implications, Kevin J. O'Sullivan, Business Science Reference (an imprint of IGI Global) ISBN 978-1-60566-679-2.

Ulrich, D. (1997). Creating the boundaryless organization: Based on a presentation by Management Forum Series speaker. 
Table 1. A general timeline of major IC practice and research milestones

\begin{tabular}{|c|c|}
\hline Period & Progress \\
\hline Early 1980 s & $\begin{array}{l}\text { - Continuing general notion of intangible value (often generically, labeled as 'goodwill') held over from the earliest } \\
\text { days of doing business. }\end{array}$ \\
\hline Mid 1980s & $\begin{array}{l}\text { - The 'information age' takes hold and the gap between book value and market value widens noticeably for many } \\
\text { companies. }\end{array}$ \\
\hline Late $1980 \mathrm{~s}$ & - Early attempts by practitioner consultants to construct statements/accounts that measure IC (Sveiby, 1988). \\
\hline Early 1990 s & $\begin{array}{l}\text { - Initiatives by certain companies (e.g. Celemi and Skandia) to systematically measure and report on company } \\
\text { stocks of IC to external parties. In 1990, Skandia AFS appoints Leif Edvinsson 'Director of IC'. This is the first time } \\
\text { that the role of managing IC is elevated to a position with formal status and given an air of corporate legitimacy. } \\
\text { - Kaplan and Norton introduce the concept of a Balanced Scorecard (1992). The Scorecard evolved around the } \\
\text { premise that 'what you measure is what you get'. }\end{array}$ \\
\hline Mid 1990s & $\begin{array}{l}\text { - Nonaka and Takeuchi (1995) present their highly influential work on 'the knowledge creating company'. Although } \\
\text { the book concentrates on 'knowledge' the distinction between knowledge and IC is sufficiently fine as to make the } \\
\text { book relevant to those with a pure focus on IC. } \\
\text { - Celemi's Tango simulation tool is launched in 1994. Tango is the first widely marketed product to enable executive } \\
\text { education on the importance of intangibles. } \\
\text { - Also in 1994, a supplement to Skandia's annual report is produced which focuses on presenting an evaluation of } \\
\text { the company's stock of IC. 'Visualizing IC' generates a great deal of interest from other companies seeking to fol- } \\
\text { low Skandia's lead (Edvinsson and Sullivan, 1996). } \\
\text { - Another sensation is caused in } 1995 \text { when Celemi uses a 'knowledge audit' to offer a detailed assessment of the } \\
\text { state of its IC. } \\
\text { - Pioneers of the IC movement publish bestselling books on the topic (Kaplan and Norton, 1996; Edvinsson and } \\
\text { Malone, 1997; Sveiby 1997). }\end{array}$ \\
\hline Late $1990 \mathrm{~s}$ & $\begin{array}{l}\text { - IC becomes a popular topic with researchers and academic conferences, working papers, and other publications } \\
\text { find an increasingly diverse audience. } \\
\text { - In } 1999 \text {, the OECD convenes an international symposium in Amsterdam on IC. }\end{array}$ \\
\hline Years 2000- 2004 & $\begin{array}{l}\text { - The Meritum project (2001-2003) involves six European countries working together to deliver guidelines for the } \\
\text { development of an IC report. } \\
\text { - The 'new' Danish guidelines are developed (Danish Agency for Trade and Industry, 2003). The guidelines relied } \\
\text { upon input from } 17 \text { Danish organizations. The aim was to guide companies in the development of their own IC } \\
\text { statements. }\end{array}$ \\
\hline $\begin{array}{l}\text { Years } 2005 \\
\text { onwards }\end{array}$ & $\begin{array}{l}\text { - Other countries develop or consider develop guidelines for intellectual capital or extended performance reporting } \\
\text { while leading global companies continue to produce IC statements. }\end{array}$ \\
\hline
\end{tabular}

Source: Cuganesan, 2010, Intellectual Capital Measurement and Reporting: Issues and Challenges for Multinational Organizations, p.79 
Table 2. Characteristics of IC- knowledge based organizations *

\begin{tabular}{|c|c|c|c|}
\hline Characteristic & Definition & Associated Best Practices & Positive Byproducts \\
\hline $\begin{array}{l}\text { Self mastery- } \\
\text { individual }\end{array}$ & $\begin{array}{l}\text { The ability to honestly and } \\
\text { openly see reality as it exists; } \\
\text { to clarify one's personal vision }\end{array}$ & $\begin{array}{l}\text { 1.Positive reinforcement } \\
\text { from role } \\
\text { models/managers } \\
\text { 2.Sharing experiences } \\
\text { 3.More interaction time } \\
\text { between supervisory levels } \\
\text { 4.Emphasis on feedback } \\
\text { 5.Balance work/non-work } \\
\text { life }\end{array}$ & $\begin{array}{l}\text { Greater commitment to the } \\
\text { organization and to work; } \\
\text { less rationalization of } \\
\text { negative events; ability to } \\
\text { face limitations and areas for } \\
\text { improvement; ability to deal } \\
\text { with change }\end{array}$ \\
\hline $\begin{array}{l}\text { Mental models } \\
\text { - individual }\end{array}$ & $\begin{array}{l}\text { The ability to compare reality } \\
\text { or personal vision with } \\
\text { perceptions; reconciling both } \\
\text { into a coherent understanding }\end{array}$ & $\begin{array}{l}\text { 1.Time for learning } \\
\text { 2.Reflective openness } \\
\text { 3.Habit of inquiry } \\
\text { 4.Forgiveness of oneself } \\
\text { 5.Flexibility/adaptability }\end{array}$ & $\begin{array}{l}\text { Less use of defensive } \\
\text { routines in work; less } \\
\text { reflexivity that leads to } \\
\text { dysfunctional patterns of } \\
\text { behavior; less avoidance of } \\
\text { difficult situations }\end{array}$ \\
\hline $\begin{array}{l}\text { Shared vision - } \\
\text { group }\end{array}$ & $\begin{array}{l}\text { The ability of a group of } \\
\text { individuals to hold a shared } \\
\text { picture of a mutually desirable } \\
\text { future }\end{array}$ & $\begin{array}{l}\text { 1.Participative openness } \\
\text { 2.Trust } \\
\text { 3.Empathy towards others } \\
\text { 4.Habit of dissemination } \\
\text { 5.Emphasis on cooperation } \\
\text { 6.A common language }\end{array}$ & $\begin{array}{l}\text { Commitment over } \\
\text { compliance, faster change, } \\
\text { greater within group trust; } \\
\text { less time spent on aligning } \\
\text { interests; more effective } \\
\text { communication flows }\end{array}$ \\
\hline $\begin{array}{l}\text { Team learning } \\
\text { - group }\end{array}$ & $\begin{array}{l}\text { The ability of a group of } \\
\text { individuals to suspend } \\
\text { personal assumptions about } \\
\text { each other and engage in } \\
\text { "dialogue" rather than } \\
\text { "discussion" }\end{array}$ & $\begin{array}{l}\text { 1.Participative openness } \\
\text { 2.Consensus building } \\
\text { 3.Top-down and } \\
\text { bottom-up communication } \\
\text { flows; } \\
\text { 4.Support over blame; } \\
\text { 5.Creative thinking }\end{array}$ & $\begin{array}{l}\text { Group self-awareness; } \\
\text { heightened collective } \\
\text { learning; learning "up and } \\
\text { down" the hierarchy; greater } \\
\text { cohesiveness; enhanced } \\
\text { creativity }\end{array}$ \\
\hline $\begin{array}{l}\text { Systems } \\
\text { thinking - } \\
\text { group }\end{array}$ & $\begin{array}{l}\text { The ability to see } \\
\text { interrelationships rather than } \\
\text { linear cause-effect; the ability } \\
\text { to think in context and } \\
\text { appreciate the consequences } \\
\text { of actions on other parts of the } \\
\text { system }\end{array}$ & $\begin{array}{l}\text { 1.Practicing self mastery } \\
\text { 2.Possessing consistent } \\
\text { mental models } \\
\text { 3.Possessing a shared } \\
\text { vision } \\
\text { 4.Emphasis on team } \\
\text { learning }\end{array}$ & $\begin{array}{l}\text { Long-term improvement or } \\
\text { change; decreased } \\
\text { organizational conflict; } \\
\text { continuous learning among } \\
\text { group members; } \\
\text { Revolutionary over } \\
\text { evolutionary change }\end{array}$ \\
\hline
\end{tabular}

Adapted from the work of Senge (1990), Argyris and Schon (1996), Argyris (1991)

Table 3. The relationship of the Physics quantum skills to key workplace challenges

\begin{tabular}{|l|l|l|l|}
\hline Challenge & Quantum skill & Definition & Behavior \\
\hline Quality & Quantum seeing & The ability to see intentionally & Focused \\
\hline Innovation & Quantum thinking & The ability to think paradoxically & Creative \\
\hline Motivation & Quantum feeling & The ability to feel vitally alive & Energetic \\
\hline Empowerment & Quantum knowing & The ability to know intuitively & Confident \\
\hline Social responsibility & Quantum acting & The ability to act responsibly & Ethical \\
\hline Change/chaos & Quantum trusting & The ability to trust life & Flexible \\
\hline Teamwork/diversity & Quantum being & The ability to be in relationship & Compassionate \\
\hline
\end{tabular}

Source: Shelton \& Darling, 2003, p.359 